\title{
FORCED-CONVECTIVE MASS TRANSFER IN VISCOELASTIC FLUID AROUND A SPHERE AND A CYLINDER
}

\author{
KOHEI OGAWA, CHIAKI KURODA AND ICHIRO INOUE \\ Department of Chemical Engineering, Tokyo Institute of Technology, Tokyo 152
}

\begin{abstract}
Key Words: Mass Transfer, Viscoelastic Fluid, Electrochemical Reaction, Polyacrylamide Solution, Sphere,
\end{abstract} Cylinder

\section{Introduction}

Many kinds of polymer solutions are often treated as non-Newtonian viscoelastic fluids, and the mass transfer around a solid body in such fluids is an important subject for the chemical industry and also for research. However, there are only a few studies ${ }^{5,6)}$ on the effects of the elastic property on mass transfer.

In this study, a polyacrylamide aqueous solution was used as an example of non-Newtonian viscoelastic fluids, and the forced-convective mass transfer around a sphere and a cylinder in uniform cross-flow was the subject for reasearch. The first objective was to measure the local mass transfer rate at many points on the bodies by using a diffusion-controlled electrochemical reaction and to compare the flow configuration around the bodies with that in other nonelastic fluids on the basis of the relationship between the velocity gradient and the diffusion-controlled mass transfer rate. The second main objective was to obtain the Sherwood number based on the total mass transfer rate by using the above experimental results and to investigate experimentally its dependence on the elastic property.

\section{Experimental}

The sphere and cylinder used were made of acrylate resin and their diameters were $19 \mathrm{~mm}$ and $20 \mathrm{~mm}$ respectively. A circular platinum electrode with a diameter of $0.2 \mathrm{~mm}$ was set on the solid surface in order to make an electrochemical reaction at a local point. The test body was fixed in a steady flow in a rotating circular channel, ${ }^{1)}$ of which the outside and inside diameters were altered to $1000 \mathrm{~mm}$ and $700 \mathrm{~mm}$. The local mass transfer rate was measured by changing the angle $\theta$ between the stagnation point and the electrode. The diameter of the supporting rod was determined so as to have little effect on the measured value of the mass transfer rate after making experiments by changing the diameter.

Received April 8, 1984. Correspondence concerning this article should be addressed to K. Ogawa.
The test fluids were aqueous solutions of polyacrylamide (PAA) with concentrations of 1.0 and $1.5 \mathrm{wt} \%$, each of which contained two electrolytes, $\mathrm{K}_{3} \mathrm{Fe}(\mathrm{CN})_{6}$ and $\mathrm{K}_{4} \mathrm{Fe}(\mathrm{CN})_{6}$, each $3.0 \times 10^{-3} \mathrm{~mol} / \mathrm{liter}$. To measure the diffusion rate of ferricyanide ions to the cathode corresponding to the point electrode on the test body was the object of this study. These test fluids can be regarded as pseudoplastic fluids and their flow curves are approximated by power-law expressions. Each value of the consistency index $K$ and the flowbehavior index $n$ of.the power-law fluid used is shown in Table 1. The modulus of shear elasticity $G$, measured by a Schwedoff rheometer, is used as an index of the elastic property and its values are shown in Table 1.

Moreover, for comparison, the same experimental investigation was carried out by using an aqueous solution of sodium carboxymethylcellulose (CMC) with a concentration of $2.0 \mathrm{wt} \%$, which has the pseudoplastic property but very little elastic property.

Here, both the PAA and CMC were ionized in aqueous solutions and increased sufficiently the electric conductivity of the test fluids as a kind of supporting electrolyte.

\section{Experimental Results and Discussion}

When the Peclet number $P e$ and the Schmidt number $S c$ take large enough values as in the present study, the relationship between the diffusioncontrolled electric current $I_{d}$ and the velocity gradient $\kappa$ on the point electrode is expressed as follows ${ }^{4)}$.

$$
I_{d}=A \kappa^{1 / 3}
$$

where $A$ is a constant depending on the electrode size, the electrolyte concentration and the diffusion coefficient. The value of $A$ can be experimentally determined for each measuring condition by calibrating the electrode with a Newtonian fluid and by using the measured value of $I_{d}$ in the test fluids of $U=0 \mathrm{~m} / \mathrm{s}$.

The distributions of $I_{d}$ for the sphere in the $1.5 \mathrm{wt} \%$ PAA solution are shown in Fig. 1, where $I_{d}$ is standardized by the value at $\theta=50$ degrees, and for 
Table 1. Properties of test fluids

\begin{tabular}{ccccc}
\hline Test fluid & $\begin{array}{c}K \\
{\left[\mathrm{Ns}^{n} / \mathrm{m}^{2}\right]}\end{array}$ & $\begin{array}{c}n \\
{[-]}\end{array}$ & $\begin{array}{c}G \\
{\left[\mathrm{~N} / \mathrm{m}^{2}\right]}\end{array}$ & $\begin{array}{c}\rho \\
{\left[10^{3} \mathrm{~kg} / \mathrm{m}^{3}\right]}\end{array}$ \\
\hline $1.0 \mathrm{wt} \%$ PAA & 1.77 & 0.344 & 2.6 & 1.0 \\
$1.5 \mathrm{wt} \%$ PAA & 5.45 & 0.292 & 5.6 & 1.0 \\
$2.0 \mathrm{wt} \% \mathrm{CMC}$ & 0.112 & 0.871 & - & 1.0 \\
\hline
\end{tabular}

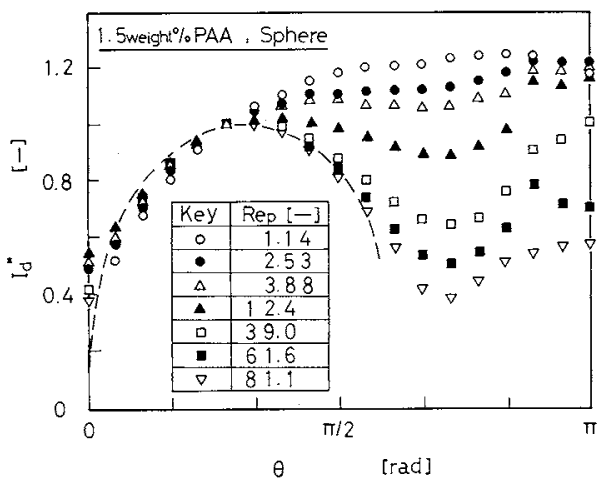

Fig. 1. Distributions of $I_{d}{ }^{*}(1.5 \mathrm{wt} \%$ PAA, sphere $)$.

comparison the results for the $2.0 \mathrm{wt} \% \mathrm{CMC}$ solution are shown in Fig. 2. The broken lines are the estimated curves for the pseudoplastic fluid, obtained by the numerical analysis of Lin et al. ${ }^{2)}$ The experimental values for the CMC solution agree well with the numerical curve in the front region of the test body. However, the experimental values for the PAA solution show a remarkable difference, not only in the back region but also in the front region. Such characteristics of the $I_{d}^{*}$ distributions are the same for the cylinder.

The remarkable difference in $I_{d}^{*}$ distributions implies a difference in the flow configuration around the test body, and is expected to depend on the elastic property of the test fluid. Here, the increase of velocity in the back side of the test body, which is related to the increase of the velocity gradient $\kappa$, is considered ${ }^{5)}$ to be the main cause of the above results, and such flow configurations are observed in visual experiments. The effect of the elastic property shows itself more strongly with the decrease of value of a dimensionless quantity $N_{e}\left(=\rho U^{2} / G\right)$ through all present experimental results including those in Fig. 1. This quantity is considered to have a meaning like the ratio of inertial force to elastic force dimensionally. And it is expected that $N_{e}$ is closely related also to the forced-convective mass transfer rate around the whole surface of the test bodies.

According to the study of Lochiel et al., ${ }^{3)}$ the Sherwood number $S h(=k d / D)$ for forced-convective mass transfer around the whole sphere surface can be calculated by using the following equation when both values of $P e$ and $S c$ are sufficiently large:

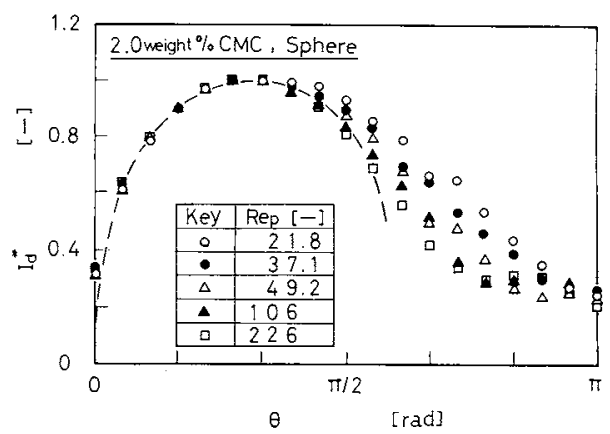

Fig. 2. Distributions of $I_{d}{ }^{*}(2.0 \mathrm{wt} \% \mathrm{CMC}$, sphere $)$.

$$
S h=0.641\left\{\int_{0}^{\pi}\left(\kappa^{*} \sin \theta\right)^{1 / 2} \sin \theta d \theta\right\}^{2 / 3} P e^{1 / 3}
$$

and a similar equation can be applied also to the cylinder:

$$
S h=0.408\left\{\int_{0}^{\pi}\left(\kappa^{*}\right)^{1 / 2} d \theta\right\}^{2 / 3} P e^{1 / 3}
$$

where $\kappa^{*}$ is the dimensionless velocity gradient $(=\kappa d / 2 U)$.

In this study, it is assumed that Eqs. (2) and (3) can be used to calculate the overall mass transfer rate because the effect of flow separation in the back region is considered to be small under the present experimental conditions. This assumption is based on two results: that the generation of flow separation was not clear by visual experiments and that the fluctuations of electric signals detected in the back region were small. As a result, the value of $S h$ will be calculated from the value of $I_{d}$ by using Eqs. (1), (2) and (3) within the limit of the present experimental conditions.

Considering that $\kappa$ is expected to be proportional to $R e_{p}^{1 /(n+1)}$ in the pseudoplastic fluid, ${ }^{2\}} S h /$ $P e^{1 / 3} \operatorname{Re}_{p}^{1 / 3(n+1)}\left(=S h / S c^{1 / 3} \operatorname{Re}_{p}^{(n+2) / 3(n+1)}, S c=P e / R e_{p}\right)$ will take a constant value from Eqs. (2) and (3). As shown in Fig. 3, this expectation is true for the CMC test fluid, but the PAA test fluid shows a different tendency. Figure 3 is for the sphere, but these characteristics are the same for the cylinder. In addition, the above-mentioned investigation was tried also for a Newtonian fluid (water, $n=1$ ), with the result that $S h$ / $S c^{1 / 3} R^{1 / 2}$ takes a constant value as before. Needless to say, the $I_{d}^{*}$ distributions for water show a remarkable difference from those for PAA solutions.

In this study, $N_{e}$ was applied to investigate the forced-convective mass transfer in the elastic fluid in addition to $R e_{p}$ and $P e$ (or $S c$ ). Good correlations between $S h / S c^{1 / 3} R e_{p}^{(n+2) / 3(n+1)}$ and $N_{e}$ were obtained for both the sphere and the cylinder, as shown in Fig. 4. Their relations can be expressed by the following experimental equations:

$$
S h=1.5 R e_{p}^{(n+2) / 3(n+1)} S c^{1 / 3} N_{e}^{-0.15}
$$




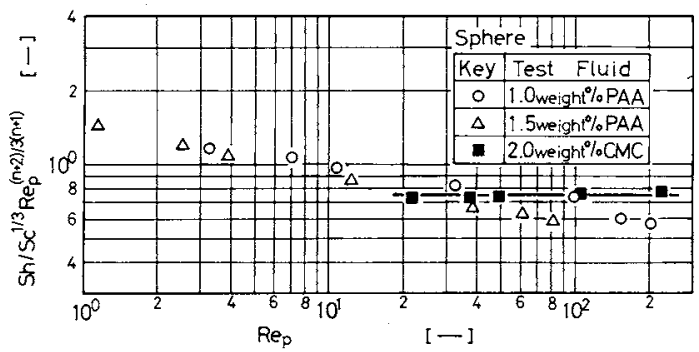

Fig. 3. Relationship between $S h / S c^{1 / 3} R e_{p}^{(n+2) / 3(n+1)}$ and $R e_{p}$ (sphere).

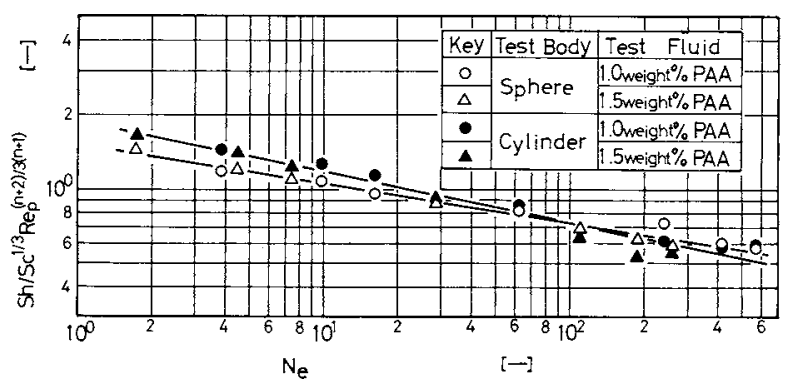

Fig. 4. Relationship between $S h / S c^{1 / 3} R e_{p}^{(n+2) / 3(n+1)}$ and $N_{e}$ (sphere and cylinder).

for a sphere

$$
\begin{gathered}
{\left[1<\operatorname{Re}_{p}<200,1<N_{e}<600\right]} \\
S h=1.9 \operatorname{Re}_{p}^{(n+2) / 3(n+1)} S c^{1 / 3} N_{e}^{-0.21}
\end{gathered}
$$

for a cylinder

$$
\left[1<R e_{p}<200,1<N_{e}<600\right]
$$

\section{Conclusion}

Forced-convective mass transfer in polymer solutions around solid bodies was experimentally investigated by determining the effect of the elastic property. It was made clear that $S h$ is proportional to $N_{e}^{-0.15}$ for a sphere and to $N_{e}^{-0.21}$ for a cylinder.

\section{Acknowledgment}

The authors wish to thank Mr. Y. Ohtake for his help in carrying out the experiments and his useful suggestions.

$\begin{array}{llr}\text { Nomenclature } & \\ A & =\text { experimental constant of Eq. }(\mathrm{l}) & {\left[\mathrm{As}^{1 / 3}\right]} \\ D & =\text { diffusion coefficient of solute in solvent } & {\left[\mathrm{m}^{2} / \mathrm{s}\right]} \\ d & =\text { diameter of sphere and cylinder } & {[\mathrm{m}]} \\ G & =\text { modulus of shear elasticity } & {\left[\mathrm{N} / \mathrm{m}^{2}\right]} \\ I_{d} & =\text { diffusion-controlled electric current } & {[\mathrm{A}]} \\ I_{d}^{*} & =I_{d} / I_{d} \text { at } \theta=50 \text { degrees } & {[-]} \\ K & =\text { consistency index of power-law fluid } & {\left[\mathrm{Ns}^{n} / \mathrm{m}^{2}\right]} \\ k & =\text { mass transfer coefficient } & {[\mathrm{m} / \mathrm{s}]} \\ N_{e} & =\rho U^{2} / G & {[-]} \\ n & =\text { flow-behavior index of power-law fluid } & {[-]} \\ P e & =\text { Peclet number, } d U / D & {[-]} \\ R e_{p} & =\text { Reynolds number of power-law fluid, } & \\ S c & =\rho U^{2-n} d^{n} / K & {[-]} \\ S h & =\text { Schmidt number, }(K / \rho D) \cdot(U / d)^{n-1} & {[-]} \\ U & =\text { Sherwood number, } k d / D & {[-]} \\ & & {[\mathrm{m} / \mathrm{s}]} \\ \theta & =\text { angular displacement from front stagnation } \\ & \text { point } & {[\mathrm{rad}]} \\ \kappa & =\text { velocity gradient at the interface } & {[1 / \mathrm{s}]} \\ \rho & =\text { density } & {\left[\mathrm{kg} / \mathrm{m}^{3}\right]}\end{array}$

\section{Literature Cited}

1) Ito, S., K. Ogawa and T. Yuhara: Kagaku Kōgaku, 37, 698 (1973).

2) Lin, F. N. and S. Y. Chern: Int. J. Heat Mass Transfer, 22, 1323 (1979).

3) Lochiel, A. C. and P. H. Calderbank: Chem. Eng. Sci., 19, 471 (1964).

4) Mizushina, T.: Advances in Heat Transfer, 7, 87 (1971).

5) Mizushina, T. and H. Usui: J. Chem. Eng. Japan, 8, 393 (1975).

6) Shirotsuka, T. and Y. Kawase: Kagaku Kōgaku, 38, 797 (1974).

(Presented at the 17th Autumn Meeting of The Society of Chemical Engineers, Japan at Sendai, October 1983.) 